\title{
GROUNDWATER REMEDIATION IN CONTAMINATED BALTIC SEA COASTAL AREA NEAR VENTSPILS CITY
}

\author{
Juris Burlakovs \\ Anete Karklina \\ University of Latvia
}

\begin{abstract}
Different solutions for groundwater treatment often are needed because of complicated hydrogeological conditions and manifold contaminants demanding distinct approaches for remediation. Various technologies of treatment can be used such as pump-and-treat, reactive barriers, chemical injections and other. Two systems were proposed for treatment of different age and fraction oil product contamination in groundwater of the Baltic Sea coastal area north from Ventspils City, in the western part of Latvia. Remediation should be performed after careful analysis of results of groundwater level and LNAPL fluctuations in the zone of direct influence of the open sea. Series of experiments using vacuum pumping system were performed in addition to the monitoring as one of the method for estimation of the close-to-sea hydrogeological conditions. Groundwater contamination, LNAPL monitoring and intensive pumping of contaminated groundwater is in progress during season 2012. Contaminated groundwater flow behavior is under the strong influence of the sea, therefore common methodology by creating artificial groundwater surface depression by vacuum pumping can be questionable and not very effective. This study gives the opportunity to evaluate efficiency of vacuum pumping treatment system for two different types of oil contamination under the strong marine influence conditions.
\end{abstract}

\section{KEYWORDS}

Groundwater contamination, remediation, vacuum pumping, hydrogeology, Baltic Sea

\section{INTRODUCTION}

In the EU there are large amount of contaminated sites [1] - number of estimated contaminated sites vary from 300,000 to 1.5 million that is due to the uncertainty of the common definition for contaminated sites, different approaches to acceptable risk levels, and exposure parameters [2]. Later on, [7] have reported that according to the European Commission the EU counts 3-5 million potentially contaminated sites and 500,000 sites known as contaminated sites. The latter needs remediation activities. Groundwater remediation technologies is a matter of great importance to eliminate historically and currently contaminated sites, improve environmental conditions in the contaminated site 
and around it as well as to reduce the risk to humans and the environment by the migration of contaminants together with groundwater. Remediation means actions taken to cleanup, mitigate, correct, abate, minimize, eliminate, control and contain or prevent a release of a contaminant into the environment in order to protect human health and the environment, including actions to investigate study or assess any actual or suspected release. Remediation may include, when appropriate and approved by the department, land use controls [8]. The noted definition shows that it is a broader term than cleanup and includes the management of a contaminant at a site so as to prevent, minimizes, or mitigates damage to human health or the environment [5]. The Law "On Pollution" (came into force on 1 July, 2001) defines the procedures in the sphere of contamination [9]. The purpose of the Law (Section 2) is to prevent or reduce harm caused to human health, property or the environment due to pollution, to eliminate the consequences of harm caused. A local government in co-operation with the relevant Regional Environmental Board of State Environmental Service has an obligation to ascertain and initially assess polluted and potentially polluted sites in a relevant administrative territory (Section 33). The Ministry of Defense has to ascertain and initially assess polluted territories in its possession and notify the relevant local government and regional environmental board thereof (Section 34).

Methods and procedures for the ascertaining of polluted and potentially polluted sites, as well as the procedures for financing, conditions for data collection and utilization are regulated by the Cabinet of Ministers Regulations No 483 adopted on November 20, 2001 "Inventory and registration of contaminated and potentially contaminated areas" [6]. Latvian Environmental, Geological and Meteorological Centre (supervised institution of Ministry of Environmental Protection and Regional Development, MEPRD) has an obligation to maintain all collected and processed information about contaminated sites. Groundwater contamination with hydrocarbons is the problem for at least two thirds of registered polluted sites in Latvia.

Two sites described in the paper are situated in the Freeport of Ventspils, which is very important oil transit port in Latvia with a long history deeply from Soviet times. Historically contamination of hydrocarbons is accumulated in this area mainly from the leaching of terminals and pipelines as well as from accidents. Geomorphology is slightly undulating and technogenically changed. Area is covered by several to ten meters thick eolian sand layer. Dunes deeper are underlayed by thick Littorina Sea fine marine sand and silt sediments [3].

Hidrogeologically the first groundwater horizon is upper groundwater and it is found in marine fine sand sediments. Groundwater level in first area closer to the sea depending of the season is at the depth of $1.5 \mathrm{~m}$ till $2.5 \mathrm{~m}$ from the surface, but in second $-2.5-4 \mathrm{~m}$. The direction of the groundwater flow is to the Baltic Sea, when western wind is dominating, saline water intrusions are common. Ground and groundwater in both areas and surroundings are strongly contaminated with hydrocarbons. The aim of remediation works in both areas described further is to diminish the contamination flow from industrial areas to the Baltic Sea, the aim of this paper is to analyze the situation and evaluate efficiency of these works.

\section{SITE REMEDIATION}

The area of remediation works is situated in western coast of Latvia of the Baltic Sea, in the northern part of the Ventspils City (Fig. 1). Since the remediation works are the 
complex of groundwater and light non-aqueous phase liquid (LNAPL) layer observations (monitoring) combined with the real-time process of the remediation, it is important to plan remediation not only before, but also during the ongoing process. The long-term, seasonal and short-term groundwater and the associated LNAPL thickness fluctuations must be measured, also the obstacle of the proximity to the sea must be taken in consideration. Measuring was done with the Solinst and Keck Interface Probe instruments.

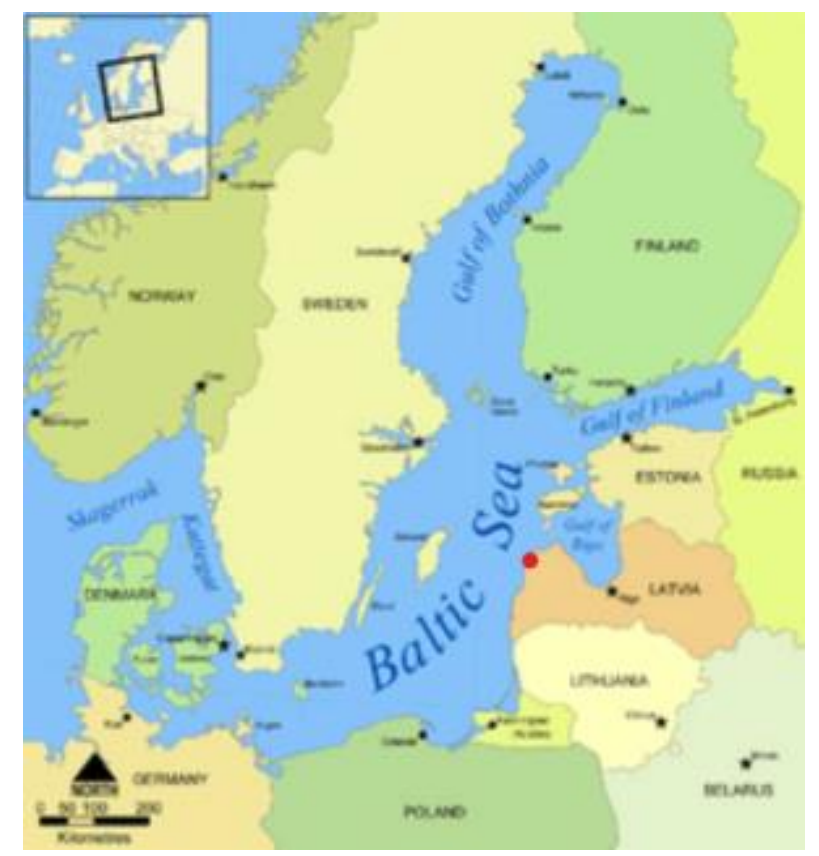

Figure 1. Location of the Remediation Area.

The remediation project contains several sub-projects, two of which are described in this paper, because must be considered to be of national importance. The first is the area near former treatment plant with its surroundings that is included in the list of polluted areas with the code 27004/2050. [4] The necessity for the realization of whole project arose from groundwater contamination in at least two sites outside industrial territories: in an area of former treatment plant and the pipeline of oil product transport, from where the contamination is migrating towards the sea. The accident in 2010 at the pipeline (Fig. 2, nr. 2) contaminated groundwater with light hydrocarbons, while the biggest part of contamination, which is found further down the sea (Fig. 1, nr. 1) have a great diversity of hydrocarbons of different age and fractions, thus approving that the historical contamination has the unstoppable movement towards the Baltic Sea from places of former accidents and ruptures. 


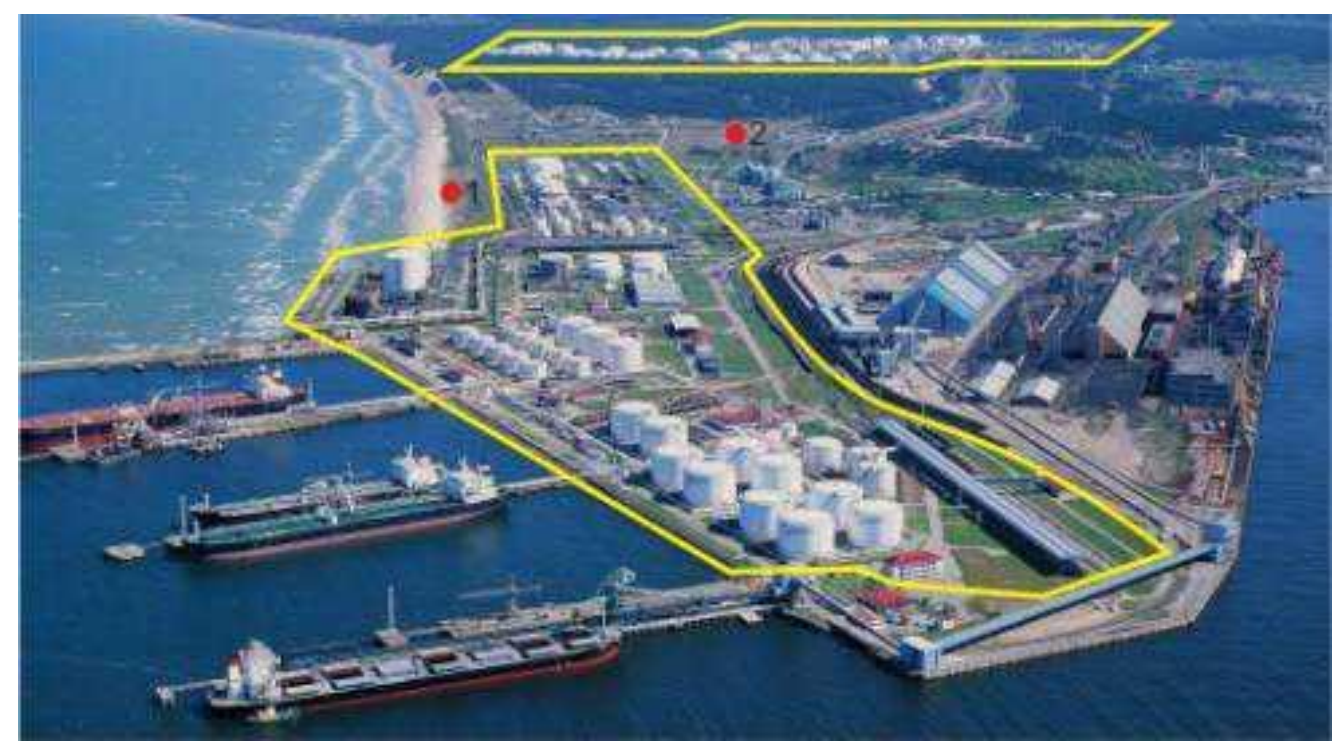

Figure 2. Location of remediation works ( $n r .1$ and 2) in the northern part of Ventspils City.

Area nearby the shore (nr.1) is widely contaminated with LNAPL consisting of hydrocarbons of different age and content. The monitoring in spring of 2012 has shown that average thickness of the LNAPL is $0.3-0.4 \mathrm{~m}$, but in some clusters of monitoring wells it reaches $1.5-1.7 \mathrm{~m}$. Thus the first decision was to implement selectively pumping through a special type of skimmer pumps, which operate on the principle of density differentiation. With the help of oil skimmers could be extracted the most part of "clean" oil from the groundwater. Skimmer in specially drilled pumping wells would intercept pollution in its path to the sea and pump it to a settling tank. Pumping modes using special oil skimmers are possible continuous, the only thing that is necessary, is adjusting the depth of immersion, when the groundwater level is fluctuating because of the groundwater-sea interactions. Remediation plan was changed and vacuum pumping is performed in season 2012. Remediation did not succeed well, since the most part of pumped liquid was groundwater, the settling tank contained just several centimeters of LNAPL, so the effect of remediation was low and unsustainable. Pump-and-treat was done using mobile vacuum pumping system and extraction was done from wells with LNAPL of the greatest thickness (approximately 15 wells). After each extraction measurements of LNAPL thickness changes were fixed in field journal and analysis showed that refilling of the wells with LNAPL of previous thickness happens in 10-15 minutes after 10-15 minutes of the extraction. Using of skimmer system would be more suitable in such hydrogeological conditions in combination with the big amount of contamination, which is supplied from the contamination plume from industrial area with surroundings of uncertain size. That is because groundwater flow is very intense, sandy sediments has good porosity and skimmer pumping can be very effective treatment as the clear oil product can be pumped out continuously.

The second area for remediation works is the main pipeline route, it is located about $1 \mathrm{~km}$ from the Baltic Sea coast, where the first area is situated (Fig. 2, nr.2). Here the problem with pipeline rupture arose in 2010 . The rupture $~ 1.5$ to $2.0 \mathrm{~m}$ depth from the ground surface was found when gasoline leaking from the rupture and became visible in the snow. The soil and groundwater is heavily contaminated with petroleum products. The immediate 
plan was needed to organize the set of measures focusing on LNAPL dissemination and movement to the Baltic Sea. The accident happened while the light hydrocarbons were transported through the pipeline and overall, the $2500 \mathrm{~m}^{2}$ big area of intense hydrocarbon spill pollution was calculated in the groundwater as well as in aeration zone. Installed groundwater monitoring wells have shown 0.32 to $0.73 \mathrm{~m}$ thick layer of floating oil in 2010. According to estimations more than $150 \mathrm{~m}^{3}$ of petroleum products leached during this one accident. Most likely, it brought together a mix of long existing "historical heavy hydrocarbon" and "fresh light hydrocarbon" pollution. There were done remediation works by pump-and-treat technology in 2010 and 2011, after that during the monitoring of 2012 were detected that LNAPL above the groundwater table does not exist anymore, contamination of groundwater is represented by dissolved oil fraction, pollution is mainly made up of gasoline, concentration maintains at a very high level (BTEX 100-10000 $\mu \mathrm{g} / \mathrm{l}$ ). Afterwards pumping system through the absorbent material was projected in order to achieve necessary environmental remediation progress with the minimum of expenses.

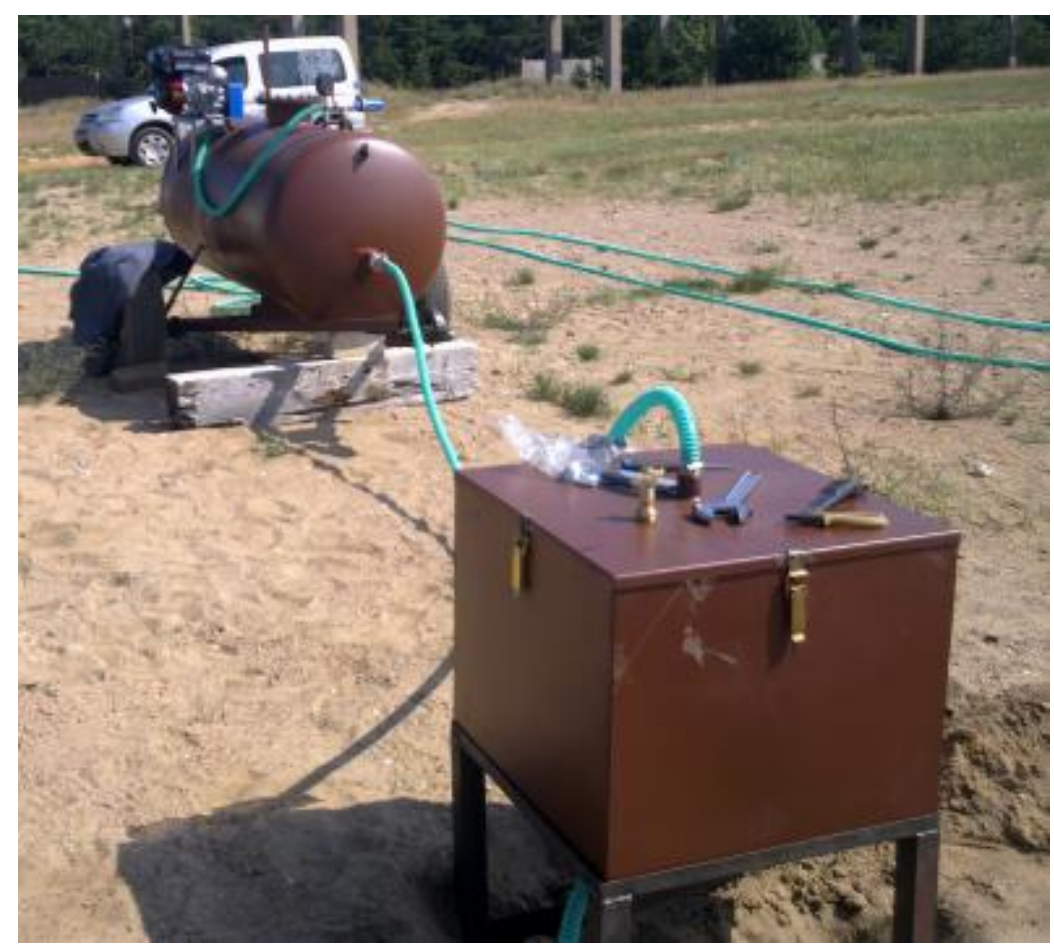

Figure 3. Pump-and-treat system using carbon powder cassettes (in the box).

However, the most effective technology for contamination with oil products in aeration zone should be soil vapor extraction with implementation of dense network oxygenenriched hot air injection holes, thus evaporation of volatile hydrocarbons from soil and groundwater would be achieved by special recovery systems. Financial aspects in this case led to the use of pump-and-treat technology using special containers / cassette absorbents (Fig.3). Groundwater is pumped through the absorbent layer in a special box designed to supply the so-called infiltration gallery and through a perforated horizontal tube (drain) rerouted into the ground for further pumping through the absorbent and rehabilitation. Carbon powder in cassettes is water repellent, absorbs oil, petroleum and chemical products. Absorbents soak up contaminant substances intensely that many times oversize own weight and successfully solves many problems of leakage. Pumping is done from 
several wells 5-8 hours a day, dislocation of the system in the whole former accident area periodically is changed in order to include whole area in remediation works.

\section{CONCLUSIONS}

The best known way for the realization of remediation of hydrocarbon contaminated sites is the use of pump-and-treat technology. The environmentally sensitive Baltic Sea is under serious threat from hazardous industrial sites such as terminals, which often are producing contamination of various hydrocarbons in groundwater through continuous or accidental leaching in former times as well as nowadays. Liquid petroleum products as the mobile layer of pollutants are moving towards the sea and thus increasing the size of environmental problems for the Baltic Sea and that is not only the local problem anymore. Remediation projects often are formal and inefficient - a new approach is recommended in order to improve the situation. World known successful technologies must be approved in practice, best available technologies for groundwater remediation, such as soil vapour extraction combined with groundwater lowering, reactive barriers and skimmer pump use must be implemented in order to achieve progress on environmental remediation.

\section{REFERENCES}

1. Critto A.,Cantarella L., Carlon C., Giove S., Petrzzelli G., Marcomini A., 2006. Decision Support-Oriented Selection of Remediation Technologies to Rehabilitate Contaminated Sites. Integrated Environmental Assessment and Management, Vol.2, No3, pp. 273-285.

2. European Commission, 2002. Towards a Thematic Strategy for Soil Protection. Brussels (Belgium). Communication from the Commission to the Council, the European Parliament, the Economic and Social Committee and the Committee of the Regions. COM 179 final.

3. Geological Map of Latvia 1:200 000. 41. Ventspils. State Geological Survey, 1998, 48 p. (in Latvian)

4. National Register of Contaminated and Potentially Contaminated Sites. LVG̣MC. Accessed: 01.07.2011. Available: http://oas.vdc.lv:7779/p_ppv.html (in Latvian).

5. Prokop G., Schamann M., Edelgaard I., 2000. Management of contaminated sites in Western Europe. Topic Report No 13/1999. European Environment Agency, Copenhagen.

6. Regulation of the Cabinet of Ministers Nr.483. Identification and Registration of Contaminated and Potentially Contaminated Sites ("LV", 171 (2558), 27.11.2001.) [in power from 28.11.2001.]; with Amendments (in Latvian).

7. Vanheusden, B., 2009. Recent Development in European Policy Regarding Brownfield Remediation. Environmental Practice, 11 (4), pp. 256-262.

8. 9VAC20-160-10. Definitions. Virginia Register Volume 13, Issue 18, eff. June 26, 1997; amended, Virginia Register Volume 18, Issue 18, eff. July 1, 2002;. Accessed: 01.07.2012. Available: http://leg1.state.va.us/cgi-bin/legp504.exe?000+reg+9VAC20-16010

9. 15.03.2001. Law "On Pollution" ("LV", 51 (2438), 29.03.2001.; Ziņotājs, 9, 03.05.2001.) [in power from 01.07.2001.]; with Amendments (in Latvian). 